\title{
Evaluasi Penggunaan Aplikasi Kahoot Pada Pembelajaran di Sekolah Dasar (SD) Pada Guru
}

\author{
Lutfi $^{1 *}$, Misriandi ${ }^{2}$, Siska Kusumawardani ${ }^{3}$, Sri Imawati ${ }^{4}$ iD \\ ${ }^{1,2,3,4}$ Prodi Pendidikan Guru Sekolah Dasar, Universitas Muhammadiyah Jakarta, Jakarta, Indonesia \\ *Corresponding author:lutfi56@gmail.com
}

\begin{abstract}
Pemahaman Kehadiran teknologi dalam berbagai kegiatan belajar mengajar menjadi lebih inovatif serta membuat suasana tidak monoton atau jenuh. Sama halnya pada dunia pendidikan memiliki tujuan mencapai efektifitas pembelajaran. Kegiatan pengabdian masyarakat yang dilakukan kepada guru-guru SD se-Sukabumi membekali pengenalan evaluasi penggunaan aplikasi kahoot sebagai alat ukur berbasis online. Pengenalan materi meliputi pemberian materi kahoot yang terdiri atas game, kuis, diskusi dan survey. Melakukan pelatihan dalam bentuk memberi tugas dan bimbingan kepada guru-guru dalam membuat soal menggunakan software kahoot untuk membuat soal evaluasi berbasis online. Melakukan diskusi dengan guruguru untuk menyelesaikan permasalahan yang dihadapi dalam menggunkan kahoot. Dalam hal ini metode ceramah, praktik dan tanya jawab digunakan pada pengbdian masyarakat ini. Kegiatan pengabdian kepada masyarakat ini menfokuskan pada pengenalan aplikasi kahoot. Berdasarkan hasil wawancara dan pengamatan langsung yang dilakukan oleh tim pengabdian bahwa guru-guru belum pernah mendapatkan materi ini dan mempraktikkan penggunaannya di kelas atau kepada peserta didik nantinya.
\end{abstract}

Keywords: Aplikasi Kahoot, Evaluasi,

\section{Abstract}

Understanding the presence of technology in various teaching and learning activities becomes more innovative and makes the atmosphere less monotonous or saturated. Likewise, in the world of education has the aims to achieving learning effectiveness. Community service activities carried out for elementary school teachers throughout Sukabumi provided an introduction to the evaluation of the use of the kahoot application as an online-based measuring tool. The introduction of the material includes giving kahoot material which consists of games, quizzes, discussions and surveys. Conduct training in the form of giving assignments and guidance to teachers in making questions using kahoot software to make online-based evaluation questions. Conducting discussions with teachers to solve problems faced in using kahoot. In this case the lecture, practice and question and answer methods are used in this community dedication. This community service activity focuses on the introduction of the kahoot application. Based on the results of interviews and direct observations made by the community service team, the teachers have never received this material and practiced using it in class or with students later.

Keywords: Kahoot Application, Evaluation

\section{Introduction}

Perkembangan ilmu pengetahuan serta teknologi pada era globalisasi sekarang ini mengalami kemajuan sangat signifikan. Kemajuan tersebut hampir memengaruhi semua sendi kehidupan. Teknologi saat ini dapat diaplikasikan pada berbagai sendi kehidupan, tanpa terkecuali pada Pendidikan (Budiman, 2013; Lubis, 2016; Pratiwi, 2014). Teknologi informasi dan komunikasi di bidang pendidikan ditandai dengan hadirnya media yang berbasis TIK dalam Pendidikan (Anih, 2016; Umar, 2016). Pemanfaatan media yang berbasis

\begin{tabular}{|c|c|c|}
\hline History: & & Publisher: Undiksha Press \\
\hline Received & : 4 Juni 2020 & Licensed: This work is licensed under \\
\hline Revised & : 11 Juli 2020 & a Creative Commons Attribution 3.0 License \\
\hline Accepted & : 21 Juli 2020 & (c) (†) (9) \\
\hline Published & : 01 Agustus 2020 & BY SA \\
\hline
\end{tabular}


TIK merupakan keharusan yang harus dilakukan untuk menunjang era persaingan kemajuan teknologi (Suradji, 2018). Penggunaan TIK di dunia Pendidikan menyebabkan perubahan mendasar dalam hal cara mengajar guru, belajar peserta didik, dan manajemen sekolah dari yang ada sebelumnya (Dewi \& Hilman, 2019; Lestari, 2015). Oleh karena itu, dapat dikatakan bahwa mengintegrasikan TIK dalam kehidupan khususnya dalam aspek pendidikan merupakan hal yang sangat penting saat ini (Istiyarti, 2017).

Mengingat pentingnya TIK, guru dituntut untuk mampu menggunakan TIK Kemampuan guru dalam mengintegrasikan TIK ke dalam pembelajaran juga akan mempengaruhi kemampuan siswa secara signifikan dalam mencapai tujuan pendidikan (Hidayat et al., 2016; Restiyani et al., 2015; Surya \& Rizal, 2019). Selain mampu menggunakan TIK sebagai sumber belajar, guru juga dituntut untuk mampu menciptakan pembelajaran kreatif dan inovatif yang terintegrasi dengan TIK (Restiyani et al., 2015). Pembelajaran yang kreatif dan menyenangkan merupakan hal yang sangat penting, karena dapat membantu siswa untuk berhasil dalam pembelajaran, menciptakan solusi dalam memecahkan masalah, sangat mempengaruhi kehidupan siswa, menimbulkan rasa senang dan puas. Kehadiran teknologi dalam berbagai kegiatan belajar mengajar membuat kegiatan belajar mengajar menjadi lebih inovatif serta membuat suasana tidak monoton atau jenuh. Sama halnya pada dunia pendidikan memiliki tujuan mencapai efektifitas pembelajaran.

Kehadiran alat-alat telekomunikasi memudahkan para peserta didik dan guru dalam mengakses informasi sehingga setiap waktu dan setiap saat dapat dengan mudah mencari bahan dan metode evaluasi beragam memanfaatkan teknologi informasi. Namun, masih ada guru yang belum bisa menguasai/menggunakan media pembelajaran modern. Ada beberapa faktor yang melatar belakangi banyaknya guru yang tidak bisa menguasai/menggunakan media pembelajaran. Pertama: guru yang menilai usia sudah masuk masa pensiun, Kedua: terlalu mendadak dan terkesan pemerintah memaksakan agar melaksanakan K13. Walaupun masih memiliki beberapa masalah terkait pada penggunaan media elektronik dalam pembelajaran, seharusnya guru bisa menciptakan suasana yang nyaman serta menyenangkan pada pembelajaran dengan peserta didik. Bila korelasikan pada kontekstual, penulis pernah merasakan kejenuhan serta kebosanan yang dialami oleh peserta didik pada menerima pelajaran. Kejenuhan terjadi saat peserta didik merasa tidak menyukai pelajaran, pendidik serta waktu jam pelajaran terakhir. Akibatnya materi yang disampaikan pendidik tidak mampu diserap secara optimal oleh peserta didik.

Efektivitas pembelajaran tidak akan tercapai, untuk mengatasi hal tersebut pendidik harus mampu mengelola kelas sehingga kondisi kelas menjadi nyaman serta menguntungkan bagi peserta didik. Pengondisian kelas ini agar dilakukan dengan cara pendidik menggunakan serta memanfaatkan aplikasi dan konten yang menunjang pembelajaran secara efektif.

Secara istilah pengertian aplikasi adalah suatu program yang siap untuk digunakan yang dibuat untuk melaksanakan suatu fungsi bagi pengguna jasa aplikasi serta penggunaan aplikasi lain yang dapat digunakan oleh suatu sasaran yang akan dituju (Andi, 2015; Niskarto Zendrato, 2017; Ridho Firmansya, Nurhadi, 2019; T et al., 2017). Contoh aplikasi yang dapat diimplementasikan dalam kegiatan pembelajaran adalah aplikasi kahoot.

Kahoot merupakan salah satu media pembelajaran interaktif yang dapat digunakan guna menjadikan proses pembelajaran menjadi menyenangkan dan tidak membosankan baik bagi peserta didik maupun bagi pengajar karena aplikasi Kahoot menekankan gaya belajar yang melibatkan hubungan peran aktif partisipasi peserta didik dengan rekan-rekan sejawatnya secara kompetitif terhadap pembelajaran yang sedang atau telah dipelajarinya (Bunyamin et al., 2020; Putri \& Muzakki, 2019; Saputra et al., 2019). Kelebihan dari Kahoot ini adalah bentuk aplikasinya berupa kuis online yang mengandung unsur persaingan karena hasil kuis dapat langsung terlihat di layar kelas sehingga dapat dijadikan motivasi belajar mahasiswa untuk memperoleh poin, serta dapat digunakan melalui berbagai media seperti 
computer, laptop, tablet dan android (Andari, 2020). Kahoot itu sendiri merupakan aplikasi permainan mendukung visual demonstrasi peserta didik pada proses pembelajaran. Pembelajaran visual lebih suka informasi yang diadakan secara visual, adalah bentuk gambar, diagram, bagan, garis waktu, film Serta berbagai demonstrasi lainnya. Jadi, aplikasi kahoot sangat efektif untuk dapat pembelajaran khususnya di Sekolah Dasar. Pendidikan di sekolah dasar sebagaiana guru dianggap sulit serta enggan mereka pelajari apa lagi guru yang sudah berusia. Pernyataan ini didukung oleh penelitian yang sudah ada.

Penelitian yang dilakukan oleh (Lisnani \& Emmanuel, 2020) proses pembelajaran menjadi lebih seru, menarik, dan menantang karena diiringi dengan musik dan waktu pengerjaan soal sehingga mahasiswa dilatih kecepatan dan ketepatan dalam menjawab soal. Nilai rata-rata kuis mahasiswa menggunakan aplikasi KAHOOT sebesar 66,69. Kedua, mahasiswa memberikan respons positif terhadap penggunaan aplikasi KAHOOT ini terlihat dari hasil kuesioner di mana sebagian mahasiswa mengharapkan penyelesaian kuis dapat dilakukan dengan menggunakan aplikasi KAHOOT kedipannya. Penelitian yang dilakukan oleh (Hartanti, 2019) aplikasi Kahoot, dalam proses pembelajaran dapat menjaga motivasi berkelanjutan belajar, sehingga tercipta suasana belajar yang lebih menarik, menyenangkan, dan tidak membosankan. Aplikasi Kahoot dapat meningkatkan minat dan motivasi siswa dalam belajar, memudahkan mereka dalam memahami materi yang diberikan oleh guru. Penelitian yang dilakukan oleh (Jumila et al., 2018) menyatakan bahwa peserta didik memiliki kategori baik pada dimensi information, communication, content-creation, dan problem solving sedangkan pada dimensi safety dikategorikan sangat baik. Dengan demikian dapat disimpulkan pemanfaatan web Kahoot dalam pembelajaran koloid dapat menumbuhkan literasi digital peserta didik. Jadi, Aplikasi kahoot adalah salah satu aplikasi yang menumbuhkan motivasi belajar, mempertajam perhatian peseta didik terhadap pelajaran.

Tujuan Pengabdian kepada masyarakat ini adalah mengevaluasi penggunaan aplikasi kahoot dalam pembelajaran di sekolah dasar pada guru SD. Memanfaatkan teknologi yang ada serta memasukkannya ke dalam kegiatan belajar mengajar. Dengan memanfaatkan teknologi untuk peserta didik diharapkan dalam dunia pendidikan mampu bersaing dengan bangsa lain dan pendidikan di Indonesia diharapkan mampu menciptakan output yang cerdas teknologi serta berpegang pada Syariah islam.

\section{Materials and Methods}

Kegiatan pengabdian masyarakat yang dilakukan kepada guru-guru SD se-Sukabumi dilaksanakan pada Tanggal 21 Januari 2020. Yang diikuti oleh guru-guru dari berbagai sekolah dasar negeri dan swasta. Sasaran pengabdian masyarakat kali ini pengenalan evaluasi penggunaan aplikasi kahoot sebagai alat ukur berbasis online. Pengenalan materi meliputi Memberikan materi Kahoot yang terdiri atas game, kuis, diskusi dan survey. Melakukan pelatihan dalam bentuk memberi tugas dan bimbingan kepada guru-guru dalam membuat soal menggunakan software Kahoot untuk membuat soal evaluasi berbasis online. Melakukan diskusi dengan guru-guru untuk menyelesaikan permasalahan yang dihadapi dalam menggunakan kahoot. Dalam hal ini metode ceramah, praktik dan tanya jawab digunakan pada pengabdian masyarakat ini.

\section{Results and Discussion}

Kegiatan Pengabdian Kepada Masyarakat ini menfokuskan pada Pengenalan aplikasi Kahoot. Hal ini merupakan hal yang baru bagi guru-guru SD di Sukabumi. Berdasarkan hasil wawancara dan pengamatan langsung yang dilakukan oleh tim pengabdi bahwa guru-guru belum pernah mendapatkan materi ini dan mempraktikkan pengguna-annya di kelas atau 
kepada peserta didik. Sementara itu, perkembangan teknologi saat ini yang sangat pesat di berbagai sektor khususnya pendidikan membuat guru-guru harus memanfaatkan dengan baik aplikasi yang mampu membuat pelajaran dikelas lebih menyenangkan. Kegiatan pemberian materi kepada guru-guru SD dapat dilihat pada Gambar 1 dan Gambar 2.

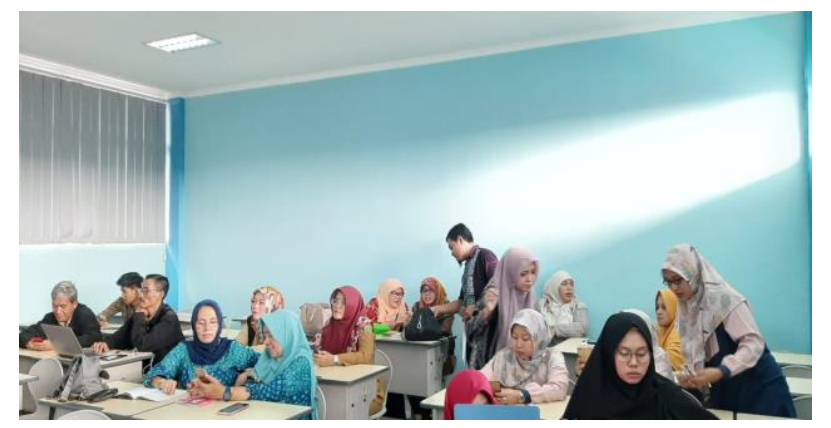

Gambar 1. Pemberian Materi kepada Guru-Guru SD

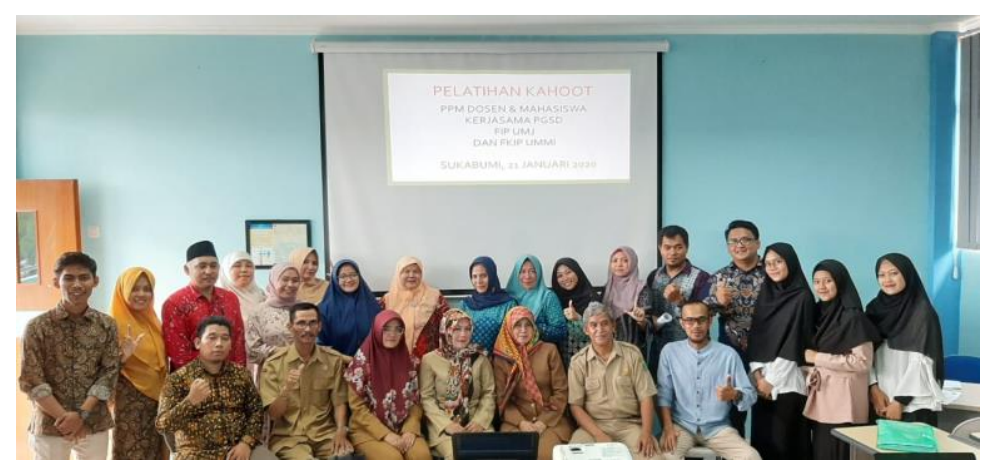

Gambar 2. Setelah melakukan Pelatihan menggunakan Kahoot

Dengan metode presentasi dan diskusi serta praktik dan pendampingan terhadap guruguru, pelatihan dilaksanakan dengan tujuan output yang dihasilkan pada pelatihan ini guruguru mempunyai ilmu yang baru dan dapat mengetahui mengenai perkembangan teknologi khususnya aplikasi kahoot yang dapat digunakan untuk membantu proses penilaian di kelas. Kegiatan PKM yang dilaksanakan di sukabumi pada guru-guru berjalan dengan baik dan lancar. Guru-guru Sekolah Dasar sebagai mitra kegiatan PKM kali ini, mendapat dukungan penuh dari pihak sekolah masing-masing yaitu kepala sekolah dan guru-guru. Hal ini tampak dari pemaparan materi yang dilakukan oleh TIM PKM mereka langsung mencoba mengaplikasikannya.

Bagi mereka pemanfaatan aplikasi kahoot yang dapat digunakan sebagai alat evaluasi menjadi hal yang nantinya membuat proses pembelajaran dikelas menjadi menyenangkan. Kahoot juga memiliki kelebihan sebagai media pembelajaran yakni suasana kelas dapat lebih menyenangkan, anak-anak dilatik untuk mengguanakn teknologi sebagai media untuk belajar, dan anak-anak di latih kemampuan motoriknya dalam pengoperasian Kahoot Selain itu sebagian sekolah dasar didukung dengan fasilitas dan pengembangan untuk menjadi sekolah smart class (Bahar et al., 2020). Kegiataan PKM yang dilaksanakan pada guru-guru SD sekota sukabumi ditemukan beberapa hal yang menjadi faktor penghambat keterlaksanaan program ini. Faktor tersebut meliputi: kemampuan guru dalam memanfaatkan fasilitas internet dan computer, jaringan internet yang cendrung tidak stabil untuk uploading data. Guru-guru yang ikut pelatihan mengaku bahwa faktor pengalaman dan kecakapan 
menggunakan software pembelajaran yang masih minim. Diharapkan kedepannya kegiatan workshop terkait pembelajaran dan evaluasi berbasis elearning ditingkatkan.

\section{Conclusion}

Kegiatan yang diikuti oleh guru-guru sekolah dasar se-sukabumi telah memiliki kemampuan menggunakan aplikasi Kahoot sebagai alat evaluasi berbasis online. 2. Penilaian dalam pelaksanaan kegiatan Program Kemitraan Masyarakat ini disambut baik dan meminta diadakan secara rutin agar proses pembelajaran di sekolah lebih efektif.

\section{References}

Andari, R. (2020). Pemanfaatan Media Pembelajaran Berbasis Game Edukasi Kahoot! Pada Pembelajaran Fisika. ORBITA: Jurnal Kajian, Inovasi Dan Aplikasi Pendidikan Fisika, 6(1), 135. https://doi.org/10.31764/orbita.v6i1.2069

Andi, J. (2015). Pembangunan Aplikasi Child Tracker Berbasis Assisted - Global Positioning System ( A-GPS ) Dengan Platform Android. Jurnal Ilmiah Komputer Dan Informatika (KOMPUTA), 1(1), 1-8. elib.unikom.ac.id/download.php?id=300375

Anih, E. (2016). Modernisasi Pembelajaran di Perguruan Tinggi Berbasis Teknologi Informasi dan Komunikasi. Jurnal Pendidikan Unsika, 7(1), 185-196. http://journal.unsika.ac.id/index.php/judika

Bahar, H., Setiyaningsih, D., Nurmalia, L., \& Astriani, L. (2020). Efektifitas Kahoot Bagi Guru Dalam Pembelajaran. KACANEGARA Jurnal Pengabdian Pada Masyarakat, 3(2), 155-162. https://doi.org/10.28989/kacanegara.v3i2.677

Budiman, A. (2013). Efisiensi Metode dan Media Pembelajaran dalam Membangun Karakter Pembelajaran Pendidikan Agama Islam. Jurnal At-Ta'dib, 8(1), 60-61. https://ejournal.unida.gontor.ac.id/index.php/tadib/article/download/514/453

Bunyamin, A. C., Juita, D. R., \& Syalsiah, N. (2020). Gunahumas Penggunaan Kahoot Sebagai Media Pembelajaran Berbasis Permaianan. Gunahumas Jurnal Kehumasan P-ISSN:, $\quad 3(1)$, $43-50$. https://ejournal.upi.edu/index.php/gunahumas/article/view/28388

Dewi, S. Z., \& Hilman, I. (2019). Penggunaan TIK sebagai Sumber dan Media Pembelajaran Inovatif di Sekolah Dasar. Indonesian Journal of Primary Education, 2(2), 48. https://doi.org/10.17509/ijpe.v2i2.15100

Hartanti, D. (2019). Meningkatkan Motivasi Belajar Siswa Dengan Media Pembelajaran Interaktif Game Kahoot Berbasis Hypermedia. Prosiding Seminar Nasional PEP 2019, 1(1), 78-85. https://jurnal.ustjogja.ac.id/index.php/snpep2019/article/view/5631

Hidayat, W., Muladi, M., \& Mizar, M. (2016). Studi Integrasi Tik Dalam Pembelajaran Di Sekolah Menengah Kejuruan. Jurnal Pendidikan - Teori, Penelitian, Dan Pengembangan, 1(12), 2281-2291. http://journal.um.ac.id/index.php/jptpp/article/download/8228/3758

Istiyarti. (2017). Pemanfaatan TIK untuk Pembelajaran. Journal of Chemical Information and Modeling, 110(9), 1689-1699. https://media.neliti.com/media/publications/286940pemanfaatan-tik-untuk-pembelajaran-08ce2c28.pdf

Jumila, PArtistiowati, Zulhipri, Z., \& Allanas, E. (2018). Analisis Literasi Digital Peserta Didik Melalui Pemanfaatan Web Kahoot dalam Pembelajaran Koloid. Jurnal Riset Pendidikan Kimia, 8(2), 36-41. https://doi.org/DOI: https://doi.org/10.21009/JRPK.082.04 Analisis 
Lestari, S. (2015). Faktor-Faktor Yang Mempengaruhi Pemanfaatan Tik Oleh Guru. Jurnal Kwangsan, 3(2), 121. https://doi.org/10.31800/jurnalkwangsan.v3i2.29

Lisnani, \& Emmanuel, G. (2020). Analisis Penggunaan Aplikasi KAHOOT dalam Pembelajaran IPA. Jurnal IPA \& Pembelajaran IPA, 4(2), 155-167. https://doi.org/10.24815/jipi.v4i2.16018

Lubis, M. (2016). Peluang Pemanfaatan Pembelajaran Berorientasi Teknologi Informasi di Lingkup Madrasah (Mempersiapkan Madrasah Berwawasan Global). Tadris: Jurnal Keguruan Dan Ilmu Tarbiyah, 1(2), 147. https://doi.org/10.24042/tadris.v1i2.1063

Niskarto Zendrato, E. Y. B. G. (2017). Pembangunan Aplikasi Runtracker Dengan Menggunakan Gps Pada Smartwatch Berbasis Android Wear. Stmikneumann, Vol 2, No, 19-24. http://ejournal.stmikneumann.ac.id/index.php/PITIN/article/view/21

Pratiwi, U. (2014). Integrasi Pendidikan Agama-Sains Berbasis Eksperimental Untuk Membentuk Character Building Mahasiswa. INSANIA : Jurnal Pemikiran Alternatif Kependidikan, 19(2), 359-384. https://doi.org/10.24090/insania.v19i2.720

Putri, A. R., \& Muzakki, M. A. (2019). Implemetasi Kahoot sebagai Media Pembelajaran Berbasis Digital Game Based Learning dalam Mengahadapi Era Revolusi Industri 4.0. Prosiding Seminar Nasional Universitas Muria Kudus, 1-7. http://pgsd.umk.ac.id/files/prosiding/2019/27__Aprilia_Riyana.pdf

Restiyani, R., Juanengsih, N., \& Herlanti, Y. (2015). Profil Pemanfaatan Teknologi Informasi Dan Komunikasi (Tik) Sebagai Media Dan Sumber Pembelajaran Oleh Guru Biologi. Edusains UIN Syarif Hidayatullah, 6(1), 49-66. https://doi.org/10.15408/es.v6i1.1100

Ridho Firmansya, Nurhadi, M. (2019). Perancangan aplikasi sig lokasi bank sampah di kota jambi berbasis android. Jurnal Ilmiah Mahasiswa Teknik Informatika, 1(4). http://ejournal.stikom-db.ac.id/index.php/jimti/article/download/784/573/

Saputra, K., Saputra, H., Mutiawani, V., \& Zulfan, Z. (2019). Pengembangan Aplikasi Kuis Pop-Up Sebagai Pembelajaran Interaktif Berbasis Android. Seminar Nasional $\begin{array}{llll}\text { APTIKOM } & \text { (SEMNASTIK) } & 2, & 188-195 .\end{array}$ https://ejournal.upi.edu/index.php/gunahumas/article/view/28388

Suradji, M. (2018). Pengembangan Teknologi Informasi Dan Komunikasi Di Bidang Kesiswaan, Kepegawaian Dan Keuangan Di Sma Muhammadiyah 1 Gresik. TA'LIM: Jurnal Studi Pendidikan Islam, 1(2), 127-151. http://ejurnal.unisda.ac.id/index.php/talim/article/view/957

Surya, A. S. P., \& Rizal, F. (2019). Hubungan Kemampuan Teknologi Informasi Komunikasi (TIK) terhadap Hasil Belajar Menggambar dengan Perangkat Lunak (MDPL) Siswa Kelas XI Jurusan Teknik Desain Pemodelan dan Informasi Bangunan (TDPIB) di SMK Negeri 1 Sumatera Barat. Journal of Civil Engineering and Vocational Education, 6(1), 1-5. http://ejournal.unp.ac.id/index.php/cived/article/view/104941

T, F., Rusmala, \& Hardiana. (2017). Rancang Bangun Aplikasi Pengenalan Profil Sekolah SMKN1 Palopo Menggunakan Teknologi Augmented Reality Berbasis Android. Jurnal Ilmiah d'Computare, $10(1)$. https://journal.uncp.ac.id/index.php/computare/article/download/1480/1318

Umar. (2016). Teknologi Informasi Dan Komunikasi: Kedudukan Dan Peranannya Dalam Pendidikan. RI'AYAH, $1(2), \quad 1-43$. https://doi.org/http://dx.doi.org/10.1016/j.scitotenv.2014.10.007 